\title{
Spatial-temporary Analysis of Climate Changing on Five Headwater Rivers in the Tibetan Plateau through the Output of GCMS
}

\author{
CHENXi ${ }^{1 \mathrm{a}}$, HAO Zhen-chun ${ }^{2}, \mathrm{JU} \mathrm{Qin}^{2}$, DAI Minglong ${ }^{1}, \mathrm{XU}$ Changjiang ${ }^{1}$
}

(1.Bureau of Hydrology, Changjiang Water Resources Commission, Wuhan 430010, China

2. State Key Laboratory of Hydrology-Water Resources and Hydraulic Engineering, HohaiUniversity, Nanjing 210098, China)

aemail: chenxi0846@126.com

\begin{abstract}
Keywords:spatial similarity, GCMs, climate change, Delta-DCSI, temperature, precipitation Abstract:The assessment of climate change due to global warming is a worldwide public concern. The impact of climate change on water resources is worth exploring for understanding the interaction between the climate and water resources and for decision-making in water resources management. In this study, a new downscaling method Delta-DCSI was introduced for downscale grids data to station fully taking into account of elements spatial variability by interpolation method of dualistic cubic surface. Then the spatial-temporary variability of GCMs' output precipitation and air temperature in this area were analyzed compared with the observed dataset during the period of 1961-1990 through similarity coefficients (i.e., Euclidean distance, Pearson correlation) and trend surface method before doing a adjusted for the chosen models. After being adjusted, the performance of MRCGCM and NCPCM in spatiotemporal simulation of air temperature and precipitation were outstanding. The forecasting period of 2001-2099 was divided into three sections, the changing trend of air temperature and precipitation in each River region during the three periods has being illustrated respectively. The results show that the air temperature in the future will have a long-term warmer trend, especially in the source region of Yangtze River, while the precipitation in this area will increase, particularly in the source region of Yellow River and Brahmaputra. It is interesting that the precipitation in the source regions of Yellow River, Yangtze River and Brahmaputra will increase as the increment of air temperature while the precipitation in the other two regions show none significant correlation with air temperature.
\end{abstract}

\section{Introduction}

The assessment of climate change due to global warming is a worldwide public concern [1]. It has significant implications for the environment, ecosystems, water resources and virtually every aspect of human life [2]. Whether we can figure out the change of regional water resources precisely is determined by a good assessment for the climate change. Currently, the best and most complex models for climate change prediction are global climate models (GCMs).However, it is not yet possible to make reliable predictions of regional hydrologic changes directly from climate models due to the coarse resolution of GCMs and the simplification of hydrologic cycle in climate models[3]. As the large differences existing in global and regional climate change scenarios, some downscaling methods are obliged to be developed to enhance the resolution from the large scale climate model to serve the regional hydrologic model. The use of different GCMs and downscaling techniques, have been widely discussed in the literature[3, 4]. There are four types of downscaling techniques: dynamics method, statistics method, the combination of dynamics and statistics, interpolation method. The interpolation methods which include linear interpolation, regional proportion method and Delta method are widely used in the climate change and hydrological cycle because they did not refer to special knowledge of climatology and large scale climate information.

When come to the simulation performance of GCMs, the spatial performance should be considered in priority when choosing specific GCM to forecast the future climate change as the error of time series are easier to be modified. Delta method couldrebuild the future scenario through the same changing rate, but it did not consider the heterogeneous characteristic of climate change in the sub-grids. Hao et al.[5]solved this problem by using Delta-DCSI method which can take fully 
advantages ofthe heterogeneouscharacteristic of climate change in the sub-grids by usinginterpolation method of dualistic cubic surface. Thus, the regional spatial distribution of climate variables could be described more precisely. The assessment of the future precipitation and air temperature characteristic would be helpful to deepen the understanding of climate change in China.In this study, the best fitting models for the study region were selected through comparing the GCMs' spatiotemporal performance in terms of mean air temperature and precipitation (1961-1990). The outputs of the selected GCMs were modified by the Delta-DCSI method.Then we predictedthe temporal and spatial distribution of air temperature and precipitation during the future period 2001-2099 in the source region of five Rivers on Tibet Plateau by the modified dataset from the selected GCMs (under three emission scenario: A1B, B1, A2).

\section{MATERIALS AND METHODOLOGY}

\section{Study area}

The Tibetan Plateau is the highest plateau inthe world with an average elevation of more than $4000 \mathrm{~m}$, huge transmeridional mountains from the north to the south located in the area. It is called the magnifier and promoter region of the global climate change due to its sensitivity and foresight for climate change [6]. The poignant geomorphic features, widespread frozen soil environment and weak human activity make the Tibetan Plateau play an important role in the research of Energy and water cycles in the Asian Monsoon system, which in turn is a major component of both the energy and water balance of the global climate[7]. Be of particular importance is the melt season, when snowmelt and evaporation occur simultaneously in different parts of the region [8]. The River source region(Figure 1) is located in Tibetan Plateau, southwest of Qinghai province. It is the cradle and water source of Yangtze River, Yellow River, LantsangRiver, Nujiang and Brahmaputra, that's so called" Source Region of Five Rivers".It also has the reputation of "Water Tower of China"[9]. This region has the extremely special and fragile eco-system.Meanwhile, it has the responsibility to make sure the eco-system environment in the middle and lower region of the Rivers and the countries in Southeast Asia safety and sustainable development[9, 10]. However, the increasing warm and dry climate combined with human activities in this region have caused glaciers decrease, lake shrinkage, runoff drop down, soil erosion, grassland deterioration and desertification more and more terrible, especially since 1980s.

\section{Data source}

In this work, the simulated monthly mean air temperature and mean precipitation information of 22 GCMs (http:// www-pcmdi.llnl.gov/ipcc/about-ipcc.Php) are provided by Intergovernmental Panel on Climate Change's (IPCC) Fourth Assessment Report (AR4) (Table 1). Monthly observations for 30 stations in this area were collected from National Meteorological Centre, China Meteorological Administration (Table 2). During the baseline period (1961-1990), the observed mean air temperature in the south of this area (around $5{ }^{\circ} \mathrm{C}$ ) is higher than that in the north $\left(-5{ }^{\circ} \mathrm{C}\right.$ ) (shown in Figure 2 left), while the observed precipitation appears decreasing from the southeast to northwest, from more than $700 \mathrm{~mm} / \mathrm{a}$ to less than $300 \mathrm{~mm} / \mathrm{a}$ (shown in Figure 2 right). In order to analysis the spatial distribution of GCMs grid data more conveniently, data was downscaled to each station taking fully advantages of sub-grids spatial distribution by Delta DCSI method. The spatiotemporal similarity characteristics can be drawn through the comparison of the observation data with GCMs during the period 1961-1990. 


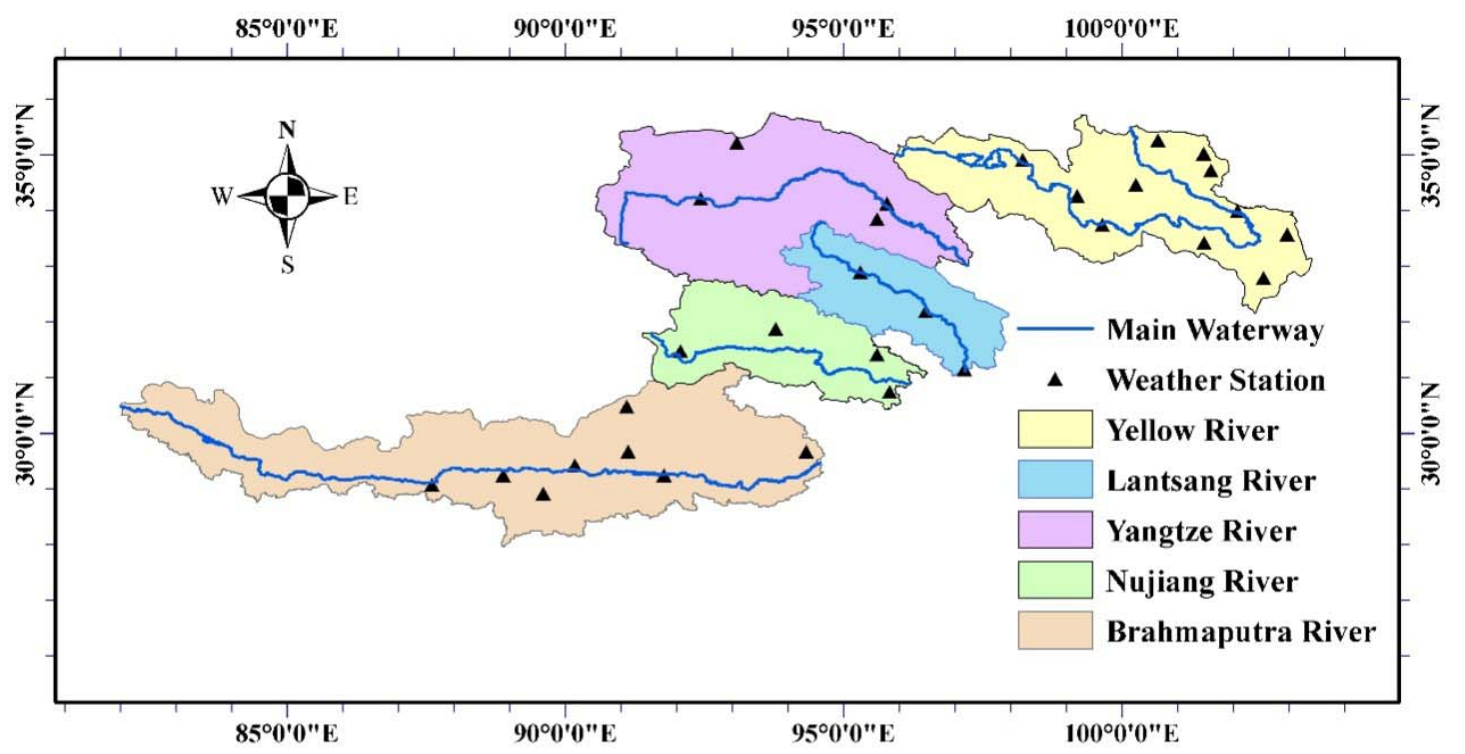

Figure1 Location of the source region of five Rivers and the observation station

Table 1 Information of 22 climate models of IPCC AR4

\begin{tabular}{|c|c|c|c|c|c|}
\hline NO. & Model name & Abbr. & Nation & Atmospheric resolution ${ }^{\circ}$ & Time period \\
\hline 1 & BCCR_BCM2.0 & BCM2 & Norway & $2.8125 \times 2.7905$ & $1850-2099$ \\
\hline 2 & CCCMA_CGCM3.1 T47 & CGMR & Canada & $3.7500 \times 3.7109$ & $1850-2300$ \\
\hline 3 & CNRM_CM3 & CNCM3 & France & $2.8125 \times 2.7906$ & $1860-2299$ \\
\hline 4 & CSIRO_Mk3.0 & CSMK3 & Australia & $1.8750 \times 1.8652$ & $1871-2200$ \\
\hline 5 & MIUB_ECHO-G & ECHOG & Germany & $3.7500 \times 3.7110$ & $1860-2100$ \\
\hline 6 & LASG_FGOALS-g1.0 & GFOALS & China & $2.8125 \times 2.7906$ & $1850-2199$ \\
\hline 7 & GFDL_CM2.0 & GFCM20 & USA & $2.5 \times 2$ & $1861-2100$ \\
\hline 8 & GFDL_CM2.1 & GFCM21 & USA & $2.5 \times 2$ & $1861-2300$ \\
\hline 9 & GISS_AOM & GIAOM & USA & $4 \times 3$ & $1850-2100$ \\
\hline 10 & GISS_E-H & GIEH & USA & $5 \times 4$ & 1880-2099 \\
\hline 11 & GISS_E-R & GIER & USA & $5 \times 4$ & $1880-2300$ \\
\hline 12 & UKMO_HadCM3 & HADCM3 & UK & $3.75 \times 2.5$ & 1860-2199 \\
\hline 13 & UKMO_HadGEM1 & HADGEM & UK & $1.875 \times 1.25$ & $1860-2100$ \\
\hline 14 & INM_CM3.0 & INCM3 & Russia & $5 \times 4$ & $1871-2200$ \\
\hline 15 & INGV_SXG2005 & INGSXG & Italy & $1.125 \times 1.125$ & $1870-2100$ \\
\hline 16 & IPSL_CM4 & IPCM4 & France & $3.75 \times 2.5352$ & $1860-2230$ \\
\hline 17 & NIES_MIROC3.2 hires & MIHR & Japan & $1.125 \times 1.1215$ & $1900-2100$ \\
\hline 18 & NIES_MIROC3.2 medres & MIMR & Japan & $2.8125 \times 2.7906$ & $1850-2300$ \\
\hline 19 & MPI-M_ECHAM5-OM & MPEH5 & Germany & $1.875 \times 1.865$ & $1960-2200$ \\
\hline 20 & MRI_CGCM2.3.2 & MRCGCM & Japan & $2.8125 \times 2.7906$ & $1851-2300$ \\
\hline 21 & NCAP_CCSM3 & NCCCSM & USA & $1.4063 \times 1.4008$ & $1870-2099$ \\
\hline 22 & NCAP_PCM & NCPCM & USA & $2.8125 \times 2.7906$ & 1890-2099 \\
\hline
\end{tabular}


Table 2The information of meteorological stations in the source region of Five rivers

\begin{tabular}{|c|c|c|c|c|c|c|c|}
\hline Sta.ID & Sta. Name & Province & Long./E & Lat./N & Elevation/m & M.T. $/{ }^{\circ} \mathrm{C}$ & M.P./mm \\
\hline 52908 & Wudaoliang & QingHai & 93.08 & 35.22 & 4612.2 & -5.6 & 265.8 \\
\hline 52957 & Tongde & QingHai & 100.65 & 35.27 & 3289.4 & 0.3 & 440.4 \\
\hline 52968 & Zeku & QingHai & 101.47 & 35.03 & 3662.8 & -2.2 & 475.8 \\
\hline 55299 & Naqu & XiZang & 92.07 & 31.48 & 4507.0 & -1.6 & 426.0 \\
\hline 55493 & Dangxiong & XiZang & 91.10 & 30.48 & 4200.0 & 1.4 & 461.5 \\
\hline 55569 & Lazi & XiZang & 87.60 & 29.08 & 4000.0 & 6.5 & 319.7 \\
\hline 55578 & Rikaze & XiZang & 88.88 & 29.25 & 3836.0 & 6.3 & 431.3 \\
\hline 55585 & Nimu & XiZang & 90.17 & 29.43 & 3809.4 & 6.7 & 343.2 \\
\hline 55591 & Lasa & XiZang & 91.13 & 29.67 & 3648.7 & 7.5 & 426.0 \\
\hline 55598 & Zedang & XiZang & 91.77 & 29.25 & 3551.7 & 8.3 & 382.5 \\
\hline 55680 & Jiangzi & XiZang & 89.60 & 28.92 & 4040.0 & 4.7 & 289.7 \\
\hline 56004 & Tuotuohe & QingHai & 92.43 & 34.22 & 4533.1 & -4.3 & 281.1 \\
\hline 56016 & Zhiduo & QingHai & 95.60 & 33.85 & 4179.0 & -1.8 & 403.9 \\
\hline 56018 & Zaduo & QingHai & 95.30 & 32.90 & 4066.4 & 0.3 & 536.2 \\
\hline 56021 & Qumalai & QingHai & 95.78 & 34.13 & 4175.0 & -2.5 & 409.1 \\
\hline 56033 & Maqu & QingHai & 98.22 & 34.92 & 4272.3 & -4.1 & 305.6 \\
\hline 56041 & Zhongxinzhan & QingHai & 99.20 & 34.27 & 4211.1 & -3.8 & 463.0 \\
\hline 56043 & Guoluo & QingHai & 100.25 & 34.47 & 3719.0 & 0.5 & 567.5 \\
\hline 56046 & Dari & QingHai & 99.65 & 33.75 & 3967.5 & -1.1 & 548.5 \\
\hline 56065 & Henan & QingHai & 101.60 & 34.73 & 3500.0 & 0.5 & 604.4 \\
\hline 56067 & Jiuzhi & QingHai & 101.48 & 33.43 & 3628.5 & 0.3 & 772.6 \\
\hline 56074 & Maqu & GangSu & 102.08 & 34.00 & 3471.4 & 1.2 & 618.8 \\
\hline 56079 & Ruoergai & sichuan & 102.97 & 33.58 & 3439.6 & 0.8 & 662.9 \\
\hline 56106 & Suoxian & XiZang & 93.78 & 31.88 & 4022.8 & 1.5 & 582.4 \\
\hline 56116 & Dingqing & XiZang & 95.60 & 31.42 & 3873.1 & 3.2 & 631.2 \\
\hline 56125 & Nangqian & QingHai & 96.48 & 32.20 & 3643.7 & 3.9 & 525.5 \\
\hline 56137 & Changdu & XiZang & 97.17 & 31.15 & 3306.0 & 7.5 & 471.9 \\
\hline 56173 & Hongyuan & SiChuan & 102.55 & 32.80 & 3491.6 & 1.2 & 765.4 \\
\hline 56223 & Luolong & XiZang & 95.83 & 30.75 & 3640.0 & 5.2 & 387.1 \\
\hline 56312 & Linzhi & XiZang & 94.33 & 29.67 & 2991.8 & 8.5 & 660.5 \\
\hline
\end{tabular}

Figure2The observed mean annual air temperature (left) and precipitation (right)during 1961-1990

\section{Methodology}

\section{Downscaling}

Delta-DCSI downscaling method was developed to improve the ability of future air temperature and precipitation scenarios on describing the spatial distribution in sub-grids. The spatial distribution of future precipitation in GCM grids was taken into account with one interpolation method of dualistic cubic surface. Its interpolation function is: 


$$
Z=f(x, y)=\sum_{i=0}^{3} \sum_{j=0}^{3} a_{i j} x^{i} y^{j}
$$

The future climate variables at each meteorological station were reconstructed by this method on the basis of which the change rate at different stations in the same grid was variable with smooth spatial distribution. Thus, it can reflect the spatial distribution characteristics of GCMs.

Precipitation and air temperature in the future period at each station were modified through comparison of the monthly variables between the future period and the reference periodfully considering the observed data. More precisely, the precipitation in the future scenario at each station is calculated by:

$$
P_{f}=P_{a} * \frac{P_{G f}}{P_{G o}}
$$

Where: $P_{f}$ is the reconstructed monthly precipitation series by Delta-DCSI method; $P_{G f}$ is the future monthly precipitation series predicted by GCMs; $\mathrm{P}_{\mathrm{Go}}$ is the monthly precipitation series in the reference period simulated by GCMs; $\mathrm{P}_{\mathrm{a}}$ is the observed average monthly precipitation series in the reference period. While the mean air temperature in the future scenario at each station is calculated by:

$$
T_{f}=T_{a}+\left(T_{G f}-T_{G o}\right)
$$

Where: $T_{f}$ is the reconstructed mean air temperature series(monthly) by Delta-DCSI method; $T_{G f i s}$ the future air temperature series predicted by GCMs; $T_{G o}$ is the series in the reference period simulated by GCMs; $T_{a}$ is the observed average air temperature series in the reference period.

\section{Spatial similarity analyze}

In this study, after downscaling to the 30 stations, monthly precipitation and mean air temperature of 22 GCMs in the reference period are compared to the observation data. The following similarity measurement indexes weretaken to analysis the spatial similarity.

\section{(1) Euclidean distance}

The Euclidean distance[11, 12]is a special form of minkowski distances which are the standard metrics for geometrical problems. In the early research of time series or space series, it was widely used.

There are two series, i.e., $\mathrm{X}=\left(\mathrm{x}_{1}, \mathrm{x}_{2}, \ldots, \mathrm{x}_{\mathrm{n}}\right)$ and $\mathrm{Y}=\left(\mathrm{y}_{1}, \mathrm{y}_{2}, \ldots, \mathrm{y}_{\mathrm{m}}\right)$, if $\mathrm{m}=\mathrm{n}$, the Euclidean distance is defined as :

$$
D(X, Y)=\sqrt{\sum_{i=1}^{n}\left(x_{i}-y_{i}\right)^{2}}
$$

the coefficient is easy to calculate while the coefficient of series common transformation remains identical (e.g., Fourier transform). The disadvantage of this method is that the length of two series should be the same.It would be sensitive about the abrupt, dislocation and shifting of the series as well.

\section{(2) Person correlation}

Person coefficient[12] is another similarity measurement, for the series $\mathrm{X}$ and $\mathrm{Y}, \mathrm{P}$ is defined as:

$$
P=\frac{\sum\left(x_{i}-\bar{X}\right)\left(y_{i}-\bar{Y}\right)}{\sqrt{\sum\left(x_{i}-\bar{X}\right)^{2}\left(y_{i}-\bar{Y}\right)^{2}}}
$$

It has a good performance when it is applied in the linear correlation, but not good in nonlinear correlation. It would be sensitive to the abrupt data of in the series as well.

\section{(3) Trend surface method}

The trend surface method [13] is good at simulating the spatial distribution of climate elements. Its regional change trend is based on mathematics models. Using this method, the point on the plane in the study area can be transformed to three-dimension graph with the attribute value clearly displayed. Then, these points should be projected to the plane orthogonal with the map plane according to latitudinal and longitudinal directions. Each direction can be fitted by a polynomial. The straight line indicates that there is no global trend, while the determined curve (e.g.,quadratic function and exponential function) suggests certain global trend. Here, we use local regression to 
illustrate trend[14].

\section{RESULT AND DISCUSSION}

\section{Performance of GCMs}

Because the spatial correction was hard to achieve, we made effort to choose models with the best spatial simulation performance before we adjusting the difference between observed data and which output from GCMs on temporary dimension.Using the observation data and GCMs data in the reference period (1961-1990), the space similarity coefficient werecalculated by the functions (4 5) which are shown in the table 3 . For mean air temperature, the best spatial simulation models were CGMR, MRCGCM, INGSXG and NCPCM (by Euclidean Distance), ECHOG,NCPCM,CGMR,NCCCSM and MRCGCM (by Person Correlation Coefficient.). For precipitation, the best spatial simulation models are IPCM4,ECOCH,MIMR,GIAOM, and INCM3 (by Euclidean Distance), CNCM3,NCPCM,MRCGCM,NCCCSM and HADCM3(by Person Correlation Coefficient).

Table 3 Spatial similarity measure results for GCMS using GCMs output in 1961-1990

\begin{tabular}{ccccc}
\hline \multirow{2}{*}{ GCMs } & \multicolumn{2}{c}{ Euclidean Distance } & \multicolumn{2}{c}{ Person Correlation Coefficient } \\
\cline { 2 - 5 } BCM2 & Mt. & Pr. & 0.01 & 0.43 \\
CGMR & 56.43 & 5063.49 & 0.7 & 0.58 \\
CNCM3 & 19.67 & 4012.5 & -0.03 & 0.76 \\
CSMK3 & 53.98 & 5315.81 & 0.04 & 0.38 \\
ECHOG & 51.95 & 1941.59 & 0.8 & -0.37 \\
GFOALS & 43.7 & 1047.36 & 0.16 & 0.31 \\
GFCM20 & 37.65 & 1548.89 & 0.03 & 0.3 \\
GFCM21 & 55.4 & 3559.64 & 0.2 & 0.52 \\
GIAOM & 41.04 & 2476.86 & -0.89 & -0.68 \\
GIEH & 42 & 1181.22 & -0.86 & -0.27 \\
GIER & 49.51 & 1336.06 & -0.86 & 0.26 \\
HADCM3 & 51.06 & 1387.49 & 0.35 & 0.61 \\
HADGEM & 31.21 & 3290.46 & 0.53 & -0.17 \\
INCM3 & 38.44 & 2759.11 & -0.89 & -0.48 \\
INGSXG & 32.95 & 1185.53 & -0.11 & -0.77 \\
IPCM4 & 25.45 & 1269.5 & -0.93 & -0.44 \\
MIHR & 54.27 & 884.63 & -0.38 & -0.09 \\
MIMR & 32.71 & 1145.56 & 0.66 & -0.38 \\
MPEH5 & 35.41 & 1207.63 & -0.09 & 0.68 \\
MRCGCM & 37.6 & 1834.54 & 0.51 & 0.66 \\
NCCCSM & 24.3 & 5893.25 & 0.56 & 0.7 \\
NCPCM & 35.5 & 2462.77 & 0.74 & \\
\hline
\end{tabular}

Note: Mt. is mean temperature; Pr. is precipitation

As for the projection trend surface method, the spatial distribution trend of observed/modelingaverage annual air temperature and precipitation were shown in Figure 3 and Figure 4, respectively.Compared with the spatial distribution trend of simulated annual air temperature and precipitation by GCMs, ECHOG and NCPCM were chosen for mean air temperature while CNCM3, MRCGCM were selected for precipitation in term of spatial simulating performance.

In general, NCPCM and MRCGCM wereoutstanding insimulating the spatial distribution of temperature and precipitation in the source region of five headwaters.Also, monthly distributions of temperature and precipitation from GCMs and observed data during the period of 1961-1990 were checked in figure 5.The two selected models behaviors good in monthly distribution. Thus, MRCGCM and NCPCM were finally selected as a representative model to predict the future climate change after the datasets were modified by equations (2-3). 


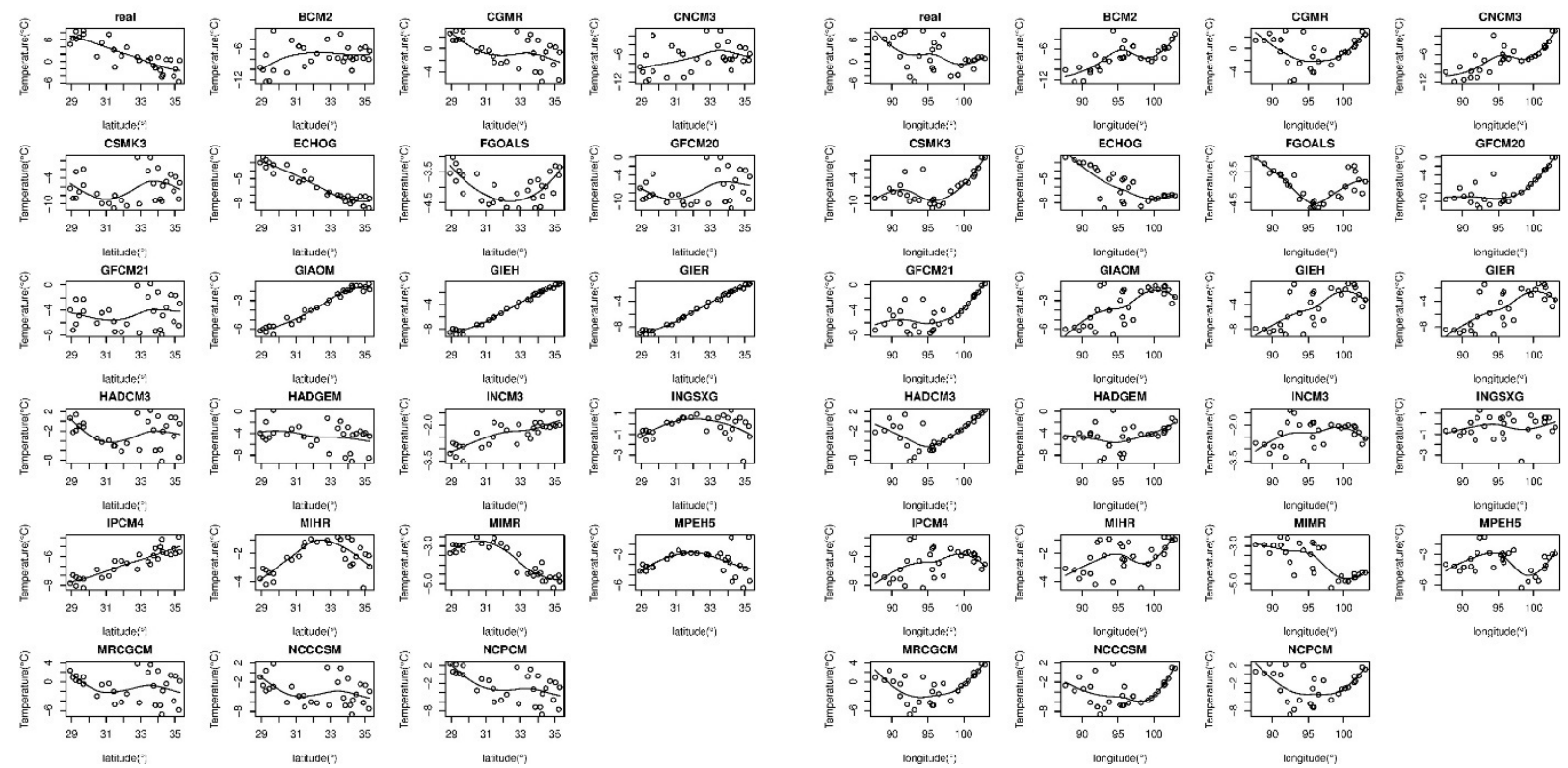

Figure 3 Spatial distribution trend of GCMs' mean annual temperature (the projection on the longitude (left)/ latitude (right) and the local regression line )
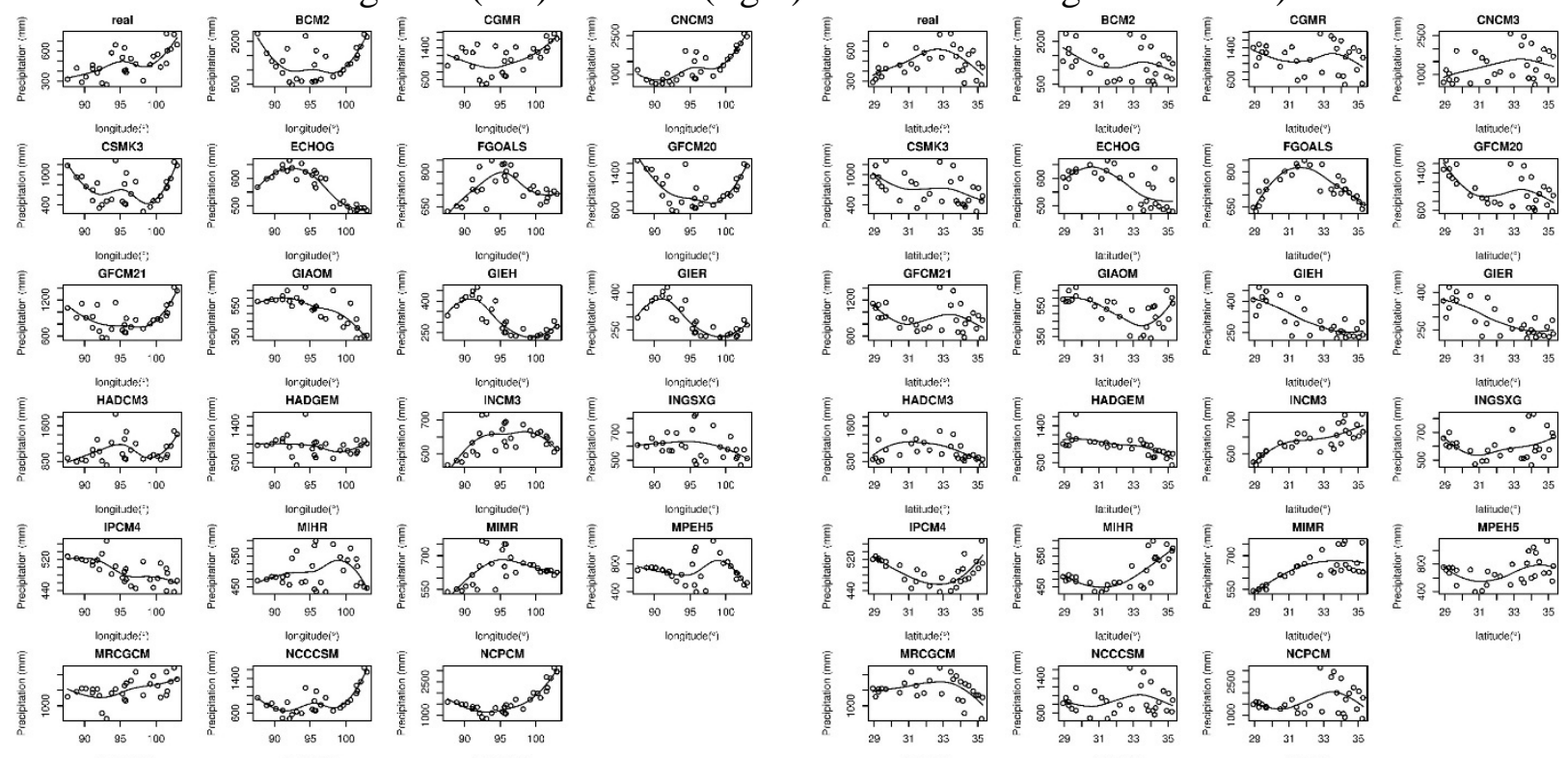

Figure 4 Spatial distribution trend of GCMs' mean annual precipitation (the projection on the longitude (left)/ latitude (right) and the local regression line)
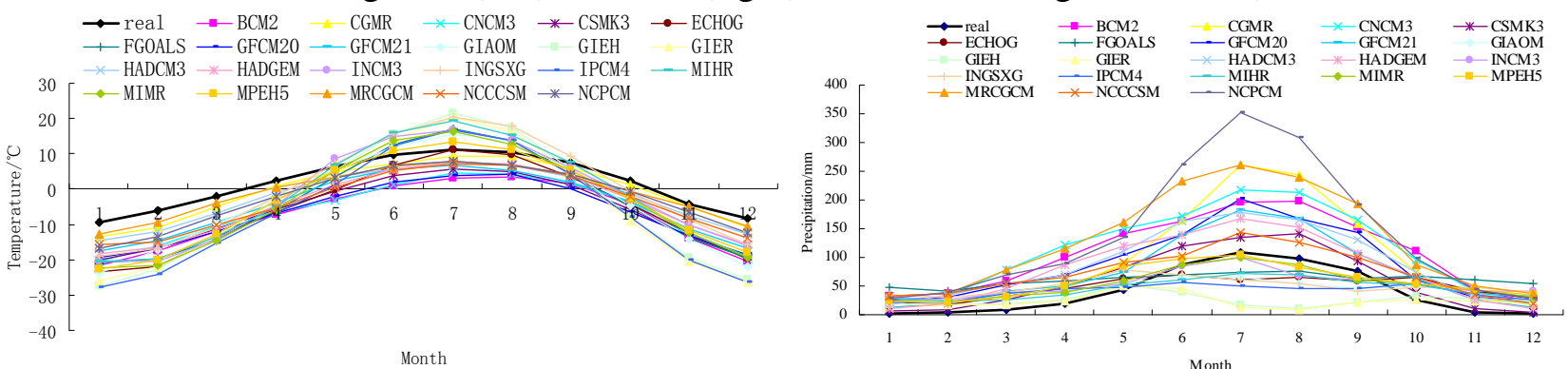

Figure 5 Monthly distributions of temperature (left) and precipitation (right) from GCMs and observed data during the period of 1961-1990

\section{Prediction for future air temperature and precipitation}

SRES refers to the scenarios described in the IPCC Special Report on Emissions Scenarios. The SRES scenarios were grouped into four scenario families (A1, A2, B1 and B2). They explored alternative development pathways, covering a wide range of demographic, economic and technological driving forces and resulting GHG emissions. The A1 storyline assumed a world of 
very rapid economic growth, a global population that would peak in mid-century and rapidly introduce more efficient technologies. A1 were divided into three groups that described alternative directions of technological change as follows: fossil intensive (A1FI), non-fossil energy resources (A1T) and a balance across all sources (A1B). B1 described a convergent world, with the same global population as $\mathrm{A} 1$, but more rapid changes in economic structures toward a service and information economy. A2 described a very heterogeneous world with high population growth, slow economic development and slow technological change [15].

In this paper, MRCGCM and NCPCM were selected to predict the future air temperature and precipitation on three scenarios (A1B, A2, and B1) in the source region of five Rivers. Before analyzing the future climatic condition, the performance of these models have been tested by using the most recent 10 years observed data and corresponding GCMs output. For yearly process of the whole region shown in Figure 6, the annual mean air temperature increased at a speed of $0.8{ }^{\circ} \mathrm{C} / 30 \mathrm{a}$, with an average annual air temperature $2.8{ }^{\circ} \mathrm{C}$ in the period 2001-2030, $3.5{ }^{\circ} \mathrm{C}$ during 2031-2060, and $4.3{ }^{\circ} \mathrm{C}$ during 2061-2089. For the annual precipitation in the whole region, all three models had a fluctuation from $400 \mathrm{~mm}$ to $500 \mathrm{~mm}$ in 2001-2030 centered at $450 \mathrm{~mm}$ which were consistent with that in 1961-1990. The period of 2031-2099 will see widely amplitude in the annual precipitation with its center value increased to about $480 \mathrm{~mm}$.

Note that A1B is the most suitable to actual circumstance; we use the average value of the two selected models (MRCGCM and NCPCM) in A1B pattern to forecast the future century climate changing in five headwater regions. Figure 7 depicted the spatial-temporary distribution of increasing percentage of temperature and precipitation for the three periods (2001-2030, 2031-2060, 2061-2099) based on the baseline period 1961-1990. Generally speaking, for temperature, it has a continuous increasing trend in the future. Through five stations in southeast (blue scatters in Lantsang River, Nujiang River and Brahmaputra River) would have smaller mean annual temperature in the period of 2001-2030 than that in the baseline period, mean annual temperature of almost all the stations in this area would be $10 \%$ larger than that in the baseline period in the next two thirty years. In the warming background, the spatial distribution of precipitation would vary in north part and south part. In most part of headwater region in Yangtze River and smaller part of Yellow River would experience a slight declining period for the first 30 years and recovery after that. But for the southern part (headwater regions for Nujiang River, Lantsang River and Brahmaputra River), the precipitation would always increasing for the three 30 years. That's very interesting that the five headwater region would not be drier and drier due to the increasing temperature as people worried about. The reason has been revealed by Jasechko et al. [16]. They used the distinct isotope effects of transpiration and evaporation to show that transpiration is by far the largest water flux from the continent of Earth, representing 80 to 90 per cent of terrestrial evapotranspiration.The five headwater region behaved the same thing as their global case.

We calculated the precise percentage of the increasing ratio of precipitation with the temperature changing in figure 8. The precipitation in the source regions of Yellow River, Yangtze River and Brahmaputra would be growing with the increment of air temperature (about $4 \%$ for the three region in 2001-2030; about 10\% for Yellow River and Yangtze River, 21\% for Brahmaputra in 2031-2060; about 22\% for Yellow River, 15\% for Yangtze River, and 26\% for Brahmaputra in 2061-2099). The precipitation in the other two regions showed no correlation with the air temperature (no more than the reference period for Lantsang River and Nujiang in 2001-2030, about 13\% and 18\% for Lantsang River and Nujiang in the period of 2031-2060 and 2061-2099). 

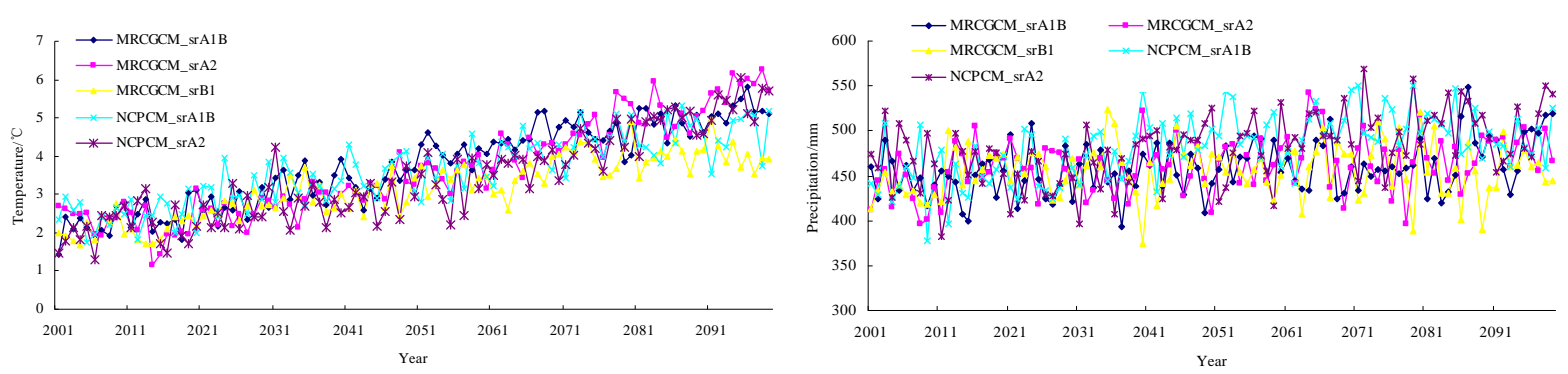

Figure6Yearly averaged temperature (left) and total precipitation (right)from 2001 to 2099 from two selected GCM models in different scenarios for the whole region
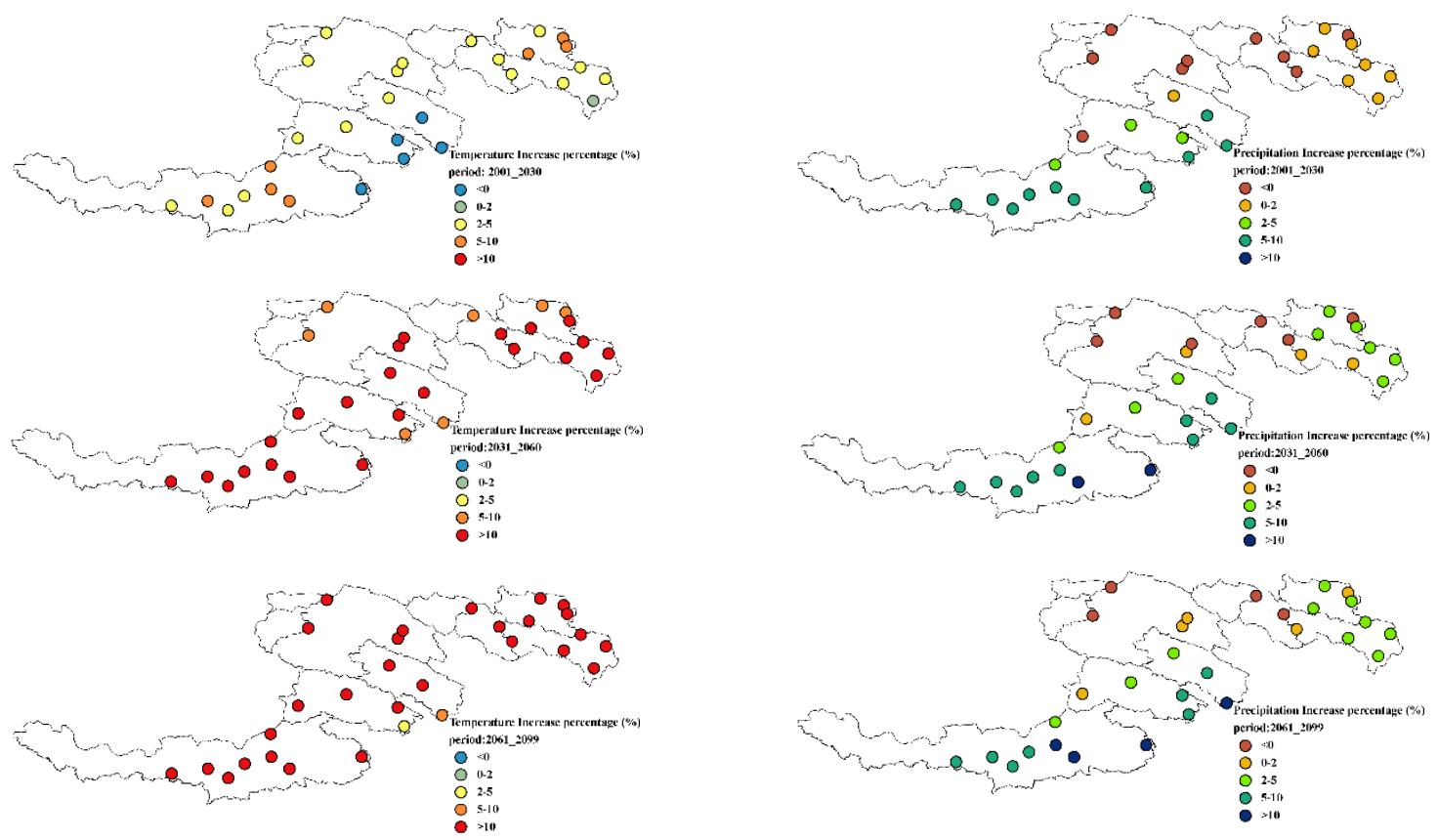

Figure 7 the increasing percentage of temperature and precipitation for the three periods(2001-2030, 2031-2060,2061-2099) based on the baseline period 1961-1990 (the left column is for temperature and the right one is for precipitation)

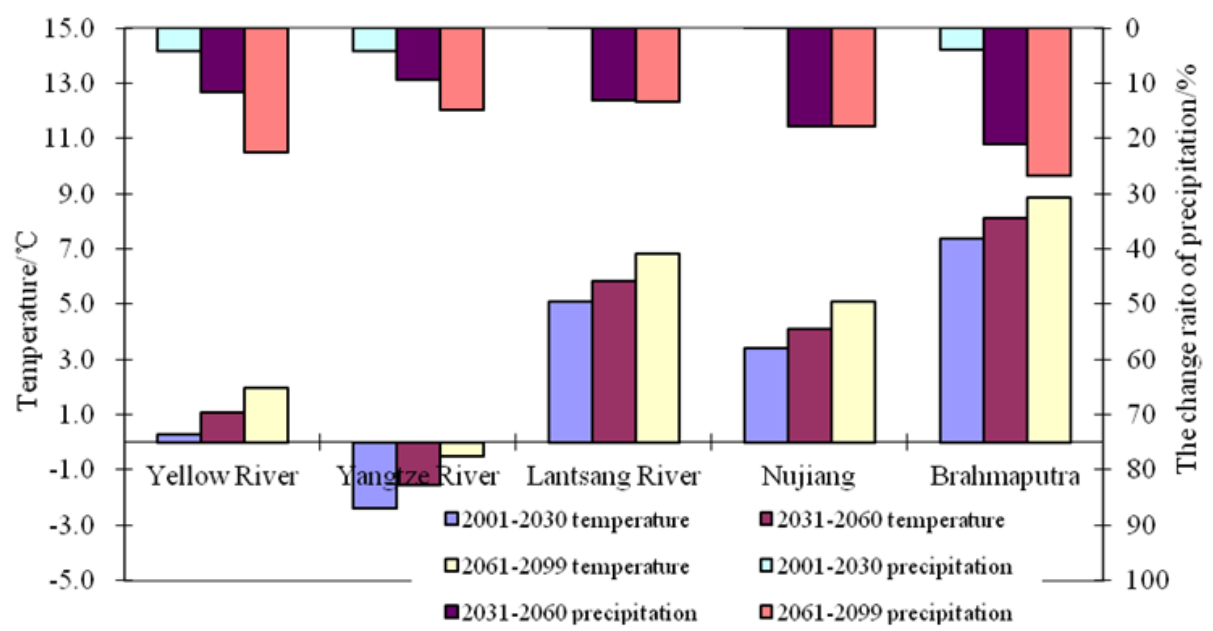

Figure8Mean annual temperature in three periodsand the changing rate of precipitation

\section{Conclusions}

In this study, the observed air temperature and precipitation in the source region of five Rivers in the Tibetan Plateau were analyzed in the reference period of 1961-1990. Similarity coefficients and 
trend surface method were carried out to compare GCMs and observation in terms of the spatial and temporal similarity on basis of Delta-DCSI downscaling method. As a consequence, MRCGCM and NCPCM were chosen to forecast the climate change in the future period of 2001-2099.In general, the warming and wetter has been identified in the future century. For yearlyprocess, the annual mean air temperature would increase at a speed of $0.8^{\circ} \mathrm{C} / 30 \mathrm{a}$. The amplitude of the annual precipitation would be wider during the period of 2031-2099 with its center increasing to about $480 \mathrm{~mm}$.As for spatial distribution of climate variables in the future, the air temperature in the source region of five Rivers would bevaried: Yangtze River would increase fastest, about $1{ }^{\circ} \mathrm{C} / 30 \mathrm{a}$ or more, Brahmaputra slowest about $0.5^{\circ} \mathrm{C} / 30 \mathrm{a}$, and the other three regions would be about $0.8^{\circ} \mathrm{C} / 30 \mathrm{a}$. The precipitation in the source regions of Yellow River, Yangtze River and Brahmaputra would be growing with the increase of air temperature (4\% for the three regions in 2001-2030; 10\% for Yellow Riverand YangtzeRiver, 21\% for Brahmaputra in 2031-2060; 22\% for Yellow River, 15\% for Yangtze River, and 26\% for Brahmaputra in 2061-2099). However, the precipitation in the other two regions seems have little responds to the increment of air temperature.Future study in this area should include the development of GIS-based models to investigate the direct relationship between environmental factors such as land use, soil, population density, and climate patterns. And all of those are further needed toenhance the ability of forecasting the change of hydrological cycle.

\section{References}

[1] Hao ZC, Ju Q, Yu ZB, Wang L, Jiang WJ. 2010. Evaluation of the simulation performance and scenario analysis for air temperature and precipitation by IPCC AR4 global climate models on Yangtze River basin. Quaternary sciences, 30(1):127-137. (In Chinese)

[2] Jiang T, Chen YQ, Xu CY, Chen XH, Chen X, VP Singh. 2007. Comparison of hydrological impacts of climate change simulated by six hydrological models in the Dongjiang Basin, South China. Journal of hydrology, 336,316-333

[3] Arora, VK. 2001. Streamflow simulations for continental-scale River basins in a global atmospheric general circulation model. Advances in Water Resources 24, 775-791.

[4] Arnell, NW. 1995. Scenarios for hydrological climate change impact studies. In: Oliver, H.R., Oliver, S.A. (Eds.), The Role of Water and the Hydrological Cycle in Global Change. Springer, Berlin, pp. 389-408.

[5] Hao ZC, Li L, Xu Y, Ju Q, Yan J, Luo J. 2009. Study on Delta-DCSI Downscaling Method of GCM Output. Journal of Sichuan University (Engineering Sicence Edition), 41(5):1-7.

[6]Liu TC, Qi M.1999. Characteristics, development and utilization prospects of water resources of the international River area in QingHai-Tibet Plateau. Acta Geographica Sinica,54,11-21.

[7] Feng S, Tang MC.1998.New evidences for climate change promotor in the Tibetan Plateau.Science in China, 43(6):633-636.

[8] Wang GX, Li YS, Wang YB, Shen YP. 2007. Impacts of alpine ecosystem and climate changes on surface runoff in the headwaters of the Yangtze River, Journal of Glaciology and Geocryology 29(2):160-168.

[9] Zhang YS, Ohata T, Kadota T. 2003. Land-surface hydrological processes in the permafrost region of the eastern Tibetan Plateau. Journal of Hydrology 283: 41-56.

[10] Shang ZH, Long RJ, Ma YS. 2007. Review on environmental problems in the headwater areas of Yangtze and Yellow Rivers in Qinghai-Tibetan Plateau.Pratacultural Science, 24(3):1-7.

[11] Dhillon, IS, Modha, DS. 2001.Concept decomposition for large sparse text data using clustering. Technical Report RJ 10147, IBM Almaden Research Center. To appear in Machine Learning. 
[12] Alexander S, Joydeep G., Raymond M. 2000. Impact of smilarity measures on web-page clustering.Workshop of Artificial Intelligence for Web Search. To appear, AAAI-2000.

[13]Feng JX. 2007. Spatial variability analysis of soil heavy metal elementon GIS and geostatisties. Changsha, Central south university of China: 42-43.

[14] Cleveland, William S.; Devlin, Susan J. 1988. Locally-Weighted Regression: An Approach to Regression Analysis by Local Fitting.Journal of the American Statistical Association83(403): 596-610.doi:10.2307/2289282

[15] IPCC, C.C., 2007. IPCC fourth assessment report (AR4). Geneva, Intergovernmental Panel on Climate Change.

[16] Jasechko S, Sharp Z D, Gibson J J, et al. Terrestrial water fluxes dominated by transpiration[J]. Nature, 2013. doi:10.1038/nature11983. 